\title{
Clinical Characteristics of Mother-Infant Dyad and Placental Pathology in COVID-19 Cases in Predominantly African American Population
}

\author{
Sanket Jani, MD ${ }^{1}$ Suzanne M Jacques, MD $\quad$ Faisal Qureshi, MD ${ }^{2} \quad$ Girija Natarajan, MD ${ }^{1}$
}

Sujit Bajaj, BS ${ }^{3}$ Pradeep Velumula, MD ${ }^{4}$ Cindy Agu, MD ${ }^{4}$ Monika Bajaj, MD ${ }^{1}$

${ }^{1}$ Department of Pediatrics, Central Michigan University School of Medicine, Children's Hospital of Michigan, Detroit, Michigan

2 Department of Pathology, Wayne State University School of Medicine, Hutzel Women's Hospital, Detroit, Michigan

${ }^{3}$ College of Osteopathic Medicine, Michigan State University, East Lansing, Michigan

${ }^{4}$ Department of Pediatrics, Children's Hospital of Michigan, Detroit, Michigan
Address for correspondence Monika Bajaj, MD, 3990 John R, Detroit, MI 48201 (e-mail: mbajaj@dmc.org).

Am J Perinatol Rep 2021;11:e15-e20.

\begin{abstract}
Keywords

- Covid-19

- placenta pathology

- vertical transmission

- perinatal effect

Objective In this currently evolving coronavirus disease 2019 (COVID-19) pandemic, the evidence is scarce about the impact of COVID-19 infection on women in labor and neonates in an inner city African-Americans (AA) population. The objective of this study was to evaluate the clinical outcomes and placental pathology in mother-infant dyads in COVID-19 cases. Study Design Retrospective chart review was conducted on 34 COVID-19 positive mother-infant dyads to study their baseline characteristics and outcomes. Placental pathology was reviewed by two perinatal pathologists.

Results COVID-19 was noted in 3\% of pregnant women who delivered in our institution. The majority (82\%) of them were asymptomatic. Out of the four mothers who were symptomatic, only three $(9 \%)$ required supplemental oxygen. None of them required invasive ventilation. All the neonates tested negative for COVID-19 at 24 hours of age. There were no gross or microscopic pathological abnormalities detected that could be definitely associated with any COVID-19 related complications during pregnancy in any of the 34 placentas.

Conclusion COVID-19 does not appear to increase morbidity and mortality among pregnant women and their neonates in a predominantly AA population. Our study did not find any evidence of vertical transmission of COVID-19 infection nor any specific findings on placental pathology.
\end{abstract}

\section{Key Points}

- Majority of women infected by coronavirus disease 2019 (COVID-19) during labor were asymptomatic.

- None of the newborns tested positive for COVID-19 at 24 hours of age.

- Placental pathology findings were nonspecific in COVID-19 mothers.

received

August 10, 2020

accepted after revision

September 24, 2020
DOI https://doi.org/ 10.1055/s-0040-1721673. ISSN 2157-6998.

\footnotetext{
(C) 2021. The Author(s).

This is an open access article published by Thieme under the terms of the Creative Commons Attribution-NonDerivative-NonCommercial-License, permitting copying and reproduction so long as the original work is given appropriate credit. Contents may not be used for commercial purposes, or adapted, remixed, transformed or built upon. (https://creativecommons.org/ licenses/by-nc-nd/4.0/)

Thieme Medical Publishers, Inc., 333 Seventh Avenue, 18th Floor, New York, NY 10001, USA
} 
Coronavirus disease 2019 (COVID-19) was declared a pandemic by World Health Organization on March 11, 2020. ${ }^{1}$ This disease has progressed rapidly and affected people of all ages, races, and ethnicities. Available data suggest that older people and people with preexisting conditions are more likely to have worse outcomes. ${ }^{2}$ This could possibly be due to inability of their immune system to mount an adequate response. Moreover, African-Americans (AAs) have disproportionately borne the burden of this disease compared with other ethnic groups. ${ }^{3-5}$ There are few studies describing the characteristics and outcomes of pregnant women affected by COVID-19 and their neonates, ${ }^{6-11}$ and the majority of the pregnant women in these reports were either of Chinese descent or Caucasians. ${ }^{9-11}$ There is a paucity of data on pregnancy outcomes in AA women affected by COVID-19.

There is lack of evidence for vertical transmission of COVID-19 in neonates. ${ }^{11,12}$ Placental pathology can be a useful tool to study the mechanism of pregnancy-related complications and associated fetal vascular or inflammatory response. Insights from placental evaluation can contribute to understanding of maternal to fetal transmission of infectious diseases. Placental pathology from seven pregnant women affected by severe acute respiratory syndrome (SARS) revealed increased intervillous and subchorionic fibrin in three cases and extensive fetal thrombotic vasculopathy in two that resulted in intrauterine growth retardation and oligohydramnios. ${ }^{13}$ There are only few reported series of placental pathology in patients diagnosed with COVID-19 during pregnancy. ${ }^{14,15}$

Our hospital is located in inner city, Detroit, and the majority of our patient population is AA. The aims of our study were twofold: first, to evaluate the clinical characteristics and pregnancy outcomes of mother-infant dyad in an inner city hospital with predominantly AA population, and second, to study the pathological findings in placentas of women affected by COVID-19 during labor.

\section{Methods}

The study and waiver of consent were approved by the institutional review board of Wayne State University. Maternal and neonatal data were collected on COVID-19 positive women delivered at Hutzel Women's Hospital, Detroit between March 11, 2020 and July 31, 2020. For the initial period, only symptomatic women received COVID-19 testing at our institution. However, starting April 21, 2020, our hospital implemented universal testing for COVID-19 in all pregnant women admitted to labor and delivery. COVID-19 reverse transcriptase polymerase chain reaction (RT-PCR) on nasopharyngeal samples was utilized for establishing diagnosis of COVID-19. Severity of the COVID was classified as per National Institute of Health guidelines. ${ }^{16}$ All proper precautions recommended by American Academy of Pediatrics ${ }^{17}$ were observed during delivery of the infant. The infant was immediately handed over to the neonatal team after delivery. Infants born to COVID-19 positive mothers were tested at 24 hours of age.
Placental histopathological evaluation was performed by two perinatal pathologists (S.M.J. or F.Q.). COVID-19 is considered an indication for placental examination at our institution, and all placentas from COVID-19 positive mothers were therefore submitted for pathologic examination. Following formalin fixation, each placenta was examined grossly and sectioned for microscopic examination in a standardized fashion. Sectioning for microscopic examination included at a minimum five cassettes with three full thickness sections of the chorionic plate, three basal plate slivers, two umbilical cord sections, and a membrane roll. Grossly identified lesions were described and sampled using additional cassettes. The tissue sections were processed in a routine manner, and sections were stained with hematoxylin and eosin. Microscopic diagnoses employed current diagnostic criteria and terminology for lesions including maternal vascular malperfusion, ${ }^{18}$ fetal vascular malperfusion, ${ }^{18}$ acute inflammatory lesions, ${ }^{18}$ and chronic inflammatory lesions. $^{19,20}$

Statistical analyses were conducted using Stata/IC 16.0 (StataCorp, College Station, TX).

\section{Results}

Thirty-four COVID-19 positive mother-infant dyads were included in our study and 29 (87\%) were AA. A total of 997 women were tested for COVID-19 after universal screening policy was instituted and 30 (3.0\%) tested positive. Four women had tested positive prior to implementation of universal screening; one developed symptoms after delivery and tested positive for COVID-19. - Table 1 describes the baseline characteristics of mother-infant dyads. Mean (standard deviation) maternal age in our cohort was 26.3 (1.3) years. Three women (9\%) had history of diabetes and five (15\%) were diagnosed with hypertension. Median (interquartile range) gestational age at delivery was 38 (37-39) weeks. One (2\%) woman developed polyhydramnios, three (9\%) developed gestational diabetes, two (6\%) had pregnancy induced hypertension, and three (9\%) had chronic hypertension. About 26/34 (76\%) had no pregnancy-related complications.

- Table 2 describes COVID-19 related data in mothers and infants. The median (range) duration between diagnosis of COVID-19 and delivery of infant was 1 (0-2) day. The diagnosis was established on the day of admission in asymptomatic women and on the day of presentation to hospital in symptomatic women. Respiratory symptoms due to COVID19 were noted in five (15\%) women: three required supplemental oxygen. Chest X-ray showed bilateral hazy opacities in all three women who required oxygen. One woman developed deep vein thrombosis. One woman received hydroxychloroquine before delivery, and one woman received steroids after delivery for management of COVID19. None of the infants were noted to have any morphological abnormality. Only one infant required positive pressure ventilation via bag and mask after delivery. Respiratory distress was noted in two infants after birth. One infant received oxygen via high-flow nasal cannula for 1 day. Chest $\mathrm{X}$-ray of this infant was suggestive of transient tachypnea of 
Table 1 Baseline characteristics of study cohort

\begin{tabular}{|c|c|}
\hline \multicolumn{2}{|l|}{ Maternal characteristics } \\
\hline Age $(y)$, mean $\pm S D$ & $26.3 \pm 1.3$ \\
\hline AA race, $n(\%)$ & $29(87)$ \\
\hline Prenatal care, $n$ (\%) & $33(97)$ \\
\hline Diabetes, $n(\%)$ & $3(9)$ \\
\hline \multicolumn{2}{|l|}{ Hypertension } \\
\hline Pregnancy induced, $n(\%)$ & $2(6)$ \\
\hline Chronic, $n(\%)$ & $3(9)$ \\
\hline $\begin{array}{l}\text { Rupture of membranes } \\
\text { duration }(\mathrm{h}), \text { median (IQR) }\end{array}$ & $1(0-5)$ \\
\hline Prenatal glucocorticoid use, $n(\%)$ & $4(12)$ \\
\hline Prenatal antibiotics use $n(\%)$ & $15(44)$ \\
\hline Cesarean delivery, $n(\%)$ & $11(32)$ \\
\hline \multicolumn{2}{|l|}{ Indication of cesarean delivery } \\
\hline Maternal, $n(\%)$ & $5(45)$ \\
\hline Fetal, $n(\%)$ & $6(55)$ \\
\hline \multicolumn{2}{|l|}{ Infant characteristics } \\
\hline Male, $n(\%)$ & $16(47)$ \\
\hline Gestational age at birth (wk), mean \pm SD & $37.8 \pm 0.4$ \\
\hline Preterm birth, $n(\%)$ & $4(12)$ \\
\hline Birth weight $(\mathrm{g})$, mean $\pm S D$ & $2,979 \pm 96$ \\
\hline Small for gestational age, $n(\%)$ & $8(23)$ \\
\hline Apgar's score at 1 minutes, median (range) & $8(6-9)$ \\
\hline Apgar's score at 5 minutes, median (range) & $9(4-9)$ \\
\hline Any resuscitation at birth, $n$ (\%) & $5(15)$ \\
\hline
\end{tabular}

Abbreviations: AA, African-Americans; IQR, interquartile range; SD, standard deviation.

newborn (TTN). Second infant was born premature at 30 weeks. He required noninvasive ventilation and his chest Xray was suggestive of respiratory distress syndrome (RDS).

Ten infants (30\%) stayed in mother's room and 24 (70\%) were separated from their mothers and kept in an isolation unit until discharge to the care of an unexposed family member. COVID-19 RT-PCR was performed on 31 (91\%) infants 24 hours after delivery and all of them tested negative. All the umbilical arterial and venous cord gases had $\mathrm{pH}$ within the normal range. Three infants $(9 \%)$ received exclusive breast milk feeding, 22 (65\%) were formula fed, and nine (26\%) received a combination of breast and formula feeding. All the mothers who provided breast milk pumped the milk taking proper precautions. None of the infants had any readmission or emergency room visit till the last day of data collection.

\section{Placental Pathology}

Nine of the 34 (26\%) placentas had no pathologic findings (-Table 3). Nine (26\%) had acute inflammatory lesions, including seven with acute maternal inflammation (four
Table 2 COVID-19 data in mother and infant

\begin{tabular}{|l|l|}
\hline \multicolumn{2}{|l|}{ Maternal data } \\
\hline $\begin{array}{l}\text { Interval between COVID-19 diagno- } \\
\text { sis and delivery (d), median (IQR) }\end{array}$ & $1(0-2)$ \\
\hline Maternal symptoms & \\
\hline Asymptomatic, $n$ (\%) & $28(82)$ \\
\hline Respiratory, $n$ (\%) & $5(15)$ \\
\hline Fever, $n$ (\%) & $2^{\text {a }}(6)$ \\
\hline $\begin{array}{l}\text { Positive chest X-ray findings for } \\
\text { COVID-19, } n \text { (\%) }\end{array}$ & $5(15)$ \\
\hline $\begin{array}{l}\text { Maternal interventions for COVID- } \\
19\end{array}$ & \\
\hline Supplemental oxygen, $n$ (\%) & $3(9)$ \\
\hline Noninvasive ventilation, $n$ (\%) & 0 \\
\hline Invasive ventilation, $n$ (\%) & 0 \\
\hline Severity of COVID-19 & $28(82 \%)$ \\
\hline Asymptomatic & $3(9 \%)$ \\
\hline Mild illness & $2(6 \%)$ \\
\hline Moderate illness & 0 \\
\hline Severe illness & 0 \\
\hline \begin{tabular}{l} 
Critical illness \\
\hline Neonatal data
\end{tabular} & 0 \\
\hline $\begin{array}{l}\text { Positive COVID-19 RT-PCR results at } \\
24 \text { h, } n \text { (\%) }\end{array}$ & $2(6)$ \\
\hline Morphological abnormality, $n$ (\%) & 0 \\
\hline $\begin{array}{l}\text { Respiratory illness after birth re- } \\
\text { quiring any supplemental oxygen, } n \\
\text { (\%) }\end{array}$ & $2(6)$ \\
\hline Chest X-ray findings & \\
\hline $\begin{array}{l}\text { Transient tachypnea of newborn, } \\
n(\%)\end{array}$ & \\
\hline RDS, $n$ (\%) & \\
\hline
\end{tabular}

Abbreviations: COVID-19, coronavirus disease 2019; IQR, interquartile range; RDS, respiratory distress syndrome; RT-PCR, reverse transcriptase polymerase chain reaction.

${ }^{\mathrm{a}}$ One Mother had both respiratory symptom and fever.

were stage 1 and three were stage 2). Only one had acute maternal inflammation grade 2 . Four of the seven placentas with acute maternal inflammation also had acute fetal inflammation, only one of which was stage 2 , and none of which were grade 2 . The remaining two had only acute funisitis; both stage 1 grade 1 and both of these had meconium histiocytosis. Eight (24\%) placentas had chronic inflammatory lesions: three had chronic lymphoplasmacytic deciduitis, four had chronic chorioamnionitis (-Fig. 1), and one had eosinophilic/T cell chorionic vasculitis involving an isolated chorionic surface the vessel (one of the placentas with chronic lymphoplasmacytic deciduitis also showed acute maternal inflammation). None of the placentas had chronic villitis. Five (15\%) placentas had lesions of maternal vascular malperfusion, including recent paracentrally 


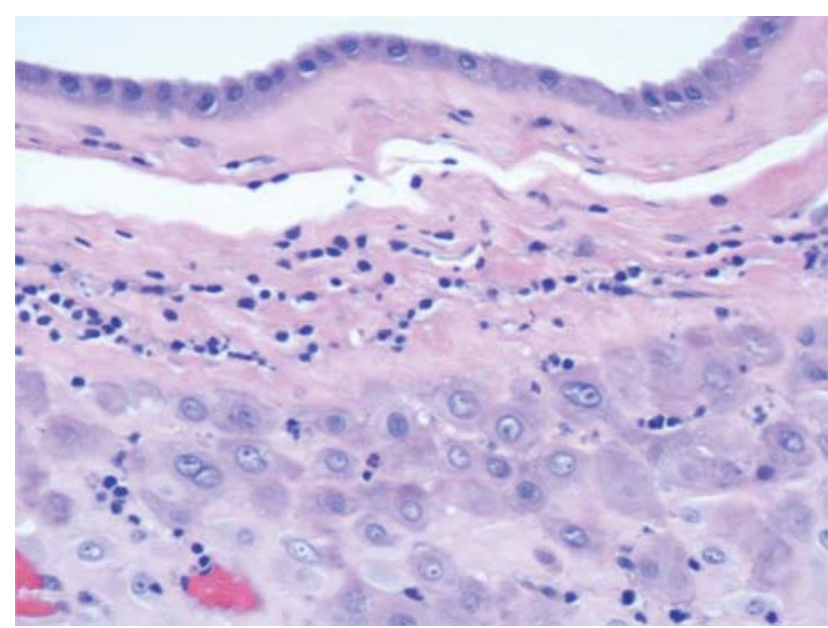

Fig. 1 Chronic chorioamnionitis. Maternal T-lymphocytes are seen infiltrating into the trophoblast layer and chorionic connective tissues of the extraplacental membranes.

located infarcts and/or retroplacental hemorrhage or hematoma, or persistent muscularization of decidua basalis blood vessels (one of these placentas also had chronic lymphoplasmacytic deciduitis). Four (12\%) placentas showed hypervascularization of chorionic villi (villous chorangiosis), one being from a mother with diabetes mellitus ( - Fig. 2). One placenta showed delayed villous maturation. Small isolated intervillous thrombi were seen in seven $(21 \%)$ placentas ( - Fig. 3), two as the sole pathologic lesion, three in placentas with acute inflammatory lesions, one in a placenta with chronic lymphoplasmacytic deciduitis, and one in a placenta with hypervascularization of chorionic villi. None of the placentas showed villous or vascular lesions of the fetal vascular malperfusion.

No definite correlation could be established between maternal/infant symptoms, severity of the maternal illness, and placental findings.

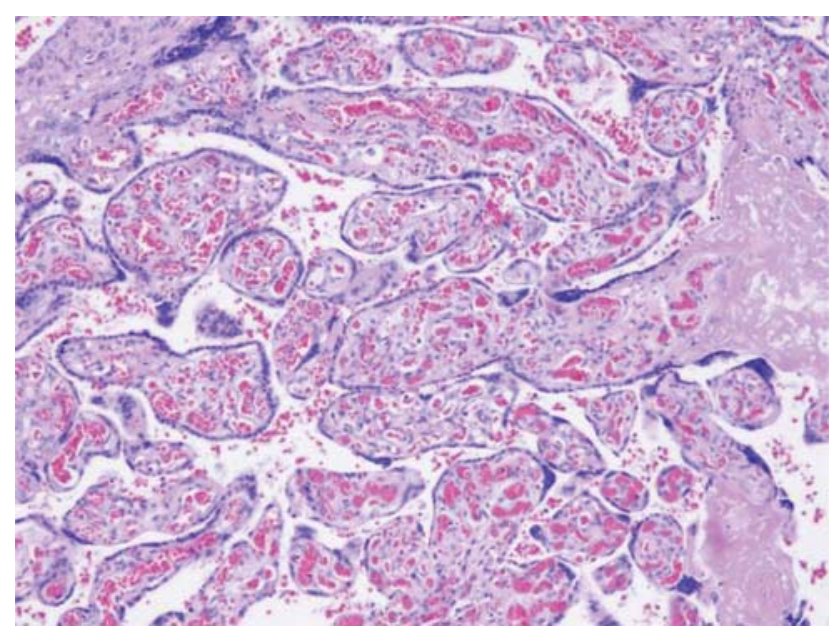

Fig. 2 Villous hypervascularization (villous chorangiosis). Increased number of capillaries are present in terminal chorionic villi.

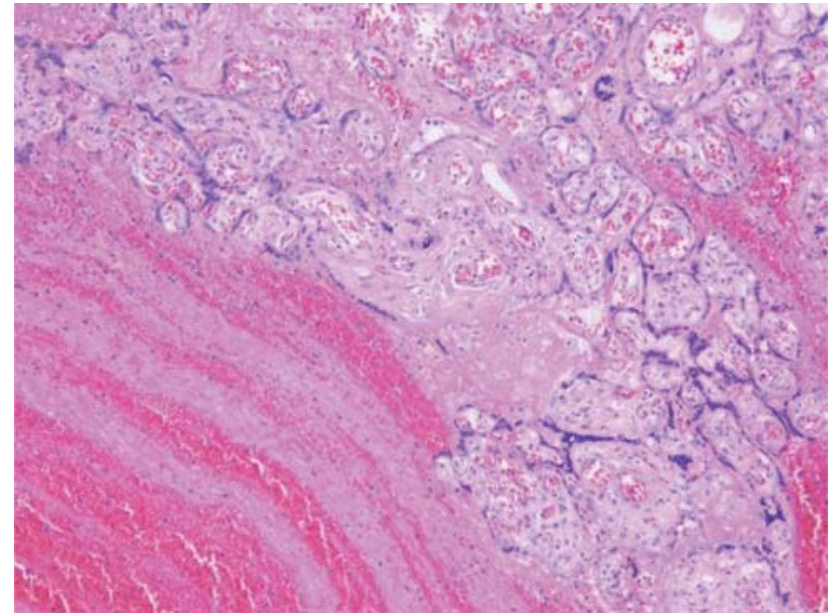

Fig. 3 Intervillous thrombus. Laminated blood clot (lower left corner) pushes and slightly compresses adjacent chorionic villi.

\section{Discussion}

Our data revealed a prevalence of 3.0\% of COVID-19 infection in pregnant women in an inner city predominantly AA population. The prevalence of COVID-19 was reported to be 13.2 and $15.5 \%$ among pregnant women in two different reports from New York. ${ }^{9,21}$ The difference in the rate could be explained by different rates of COVID-19 spread and intensity in different regions at different times. Our population was comprised of predominantly (87\%) AA women with three (9\%) Asian women originally from Bangladesh, one (2\%) woman of Middle Eastern descent, and one (2\%) Caucasian woman. The majority of the women were asymptomatic. Only six (18\%) women had symptoms, six $(9 \%)$ women required supplemental oxygen, and none of them required invasive ventilation. Our study suggests that severity and outcomes of pregnancies affected by COVID-19 in a population of AAs, and other ethnic minorities are similar to other racial groups. Elshafeey et al reviewed data from 33 studies comprising 385 pregnant women infected by COVID$19 .^{22}$ Mild symptoms were reported in $96 \%$ cases and $0.3 \%$ women were critical; one neonatal death was reported out of 252 births. A multicenter study from Italy on 77 hospitalized pregnant women showed moderate-to-severe respiratory illness in $18 \%$ of these women with $8 \%$ requiring ICU admission. ${ }^{10}$ However, this study had inherent selection bias as only symptomatic women or women who had close contact with known or suspect COVID-19 person were included.

All women in our study contracted the virus in the third trimester since all of them received RT-PCR test that can detect viral RNA on day 1 of infection and stay positive until 3 weeks. ${ }^{23}$ We did not find any evidence of vertical or perinatal transmission of COVID-19 in our study. Vertical transmission of COVID-19 has been suggested in a few studies. ${ }^{7,8,24}$ However, a recent systematic review found no evidence of vertical transmission of SARS-CoV2 infection. ${ }^{25}$ The majority of the infants (65\%) in our study were delivered vaginally, 
Table 3 Placental pathology of COVID-19 positive mothers

\begin{tabular}{|l|l|}
\hline Placenta pathology & No. of mothers (\%) \\
\hline Normal placenta & $9(26)$ \\
\hline Acute placental lesion & \\
\hline Maternal & $7(21)$ \\
\hline Fetal & $6(18)$ \\
\hline Both & $4(12)$ \\
\hline Chronic placenta lesion & $8(24)$ \\
\hline Maternal vascular malperfusion & $5(15)$ \\
\hline Fetal vascular malperfusion & 0 \\
\hline Small intervillous thrombi & $7(20)$ \\
\hline $\begin{array}{l}\text { Hypervascularization of } \\
\text { chorionic villi }\end{array}$ & $4(12)$ \\
\hline
\end{tabular}

suggesting the safety of vaginal delivery in COVID positive women. We did not perform antibody testing in pregnant women or their infants. However, all the infants were clinically stable and did not require any medical intervention. The need for supplemental oxygen in two infants was likely due to TTN and RDS.

As this pandemic evolves and more pregnant women get exposed during first and second trimesters, the neonatal manifestations might vary. In a study by Wong et al on maternal and neonatal outcomes in 12 pregnant women with SARS-CoV, spontaneous abortion was reported in four women who contracted the virus in the first trimester and four out of five women who got infected after 24 weeks delivered preterm. ${ }^{26}$ Neonatal outcomes in these cases correlated with the timing of viral exposure during pregnancy and severity of maternal symptoms.

The placental lesions in our study were varied, and only one of the acute maternal inflammatory lesions was high grade. Acute and chronic inflammatory lesions were identified in nine $(26 \%)$ and eight (24\%) of placentas, respectively, and lesions of maternal vascular malperfusion were identified in five $(15 \%)$ placentas. No chronic villitis was identified within any of the placentas. While chronic inflammatory lesions of the placenta can be an indication of infection, a growing body of evidence supports these lesions as being of immune origin (maternal antifetal rejection) in a majority of cases. ${ }^{27}$ Lowgrade placental lesions are commonly encountered in normal pregnancy outcome. A recent study at our institution of 944 term pregnancies with normal outcomes showed acute and chronic placental inflammatory lesions and lesions of maternal and fetal vascular malperfusion in 42.3, 29.9, 35.7, and $19.7 \%$, respectively, of the placentas. ${ }^{28}$ This indicates that mild placental lesions, as were seen in the placentas in this current series, are frequent findings in normal pregnancies that can be the result of changes associated with parturition or be the result of subclinical processes that did not affect the course of the pregnancy. ${ }^{27}$ It is interesting to note that four $(12 \%)$ placentas in this series showed villous hypervascularization (villous chorangiosis). This lesion is reportedly seen in 5 to $10 \%$ of term placentas, ${ }^{29,30}$ and is associated with decreased maternal oxygen tension in the presence of normal perfusion of the intervillous space (preplacental hypoxia). ${ }^{31,32}$ In this series, one of the mothers with villous hypervascularization had diabetes mellitus, and the villous hypervascularization did not correlate with respiratory symptoms in any of the mothers. It is also notable that although one placenta showed overcoiling of the umbilical cord, none of the placentas in this series showed villous or vascular lesions of fetal vascular malperfusion, including fetal vascular thrombosis or avascular villi. This is in contrast to the recent findings of Baergen et al, who reported evidence of fetal vascular malperfusion, including fetal vascular thrombosis, in 10 of 20 cases. ${ }^{14}$ Another recent report of placentas from 16 COVID-19 mothers reported an increase in lesions of maternal vascular malperfusion, including decidual arteriopathy, but no significant increase in lesions of fetal vascular malperfusion when compared with controls. ${ }^{15}$ The reason for these differences in placental findings is not clear.

Our study is the first of its kind to report pregnancy outcomes in a predominant AA inner city population. Our study is limited by its small sample size. Nonetheless, it provides important information on pregnancy-related outcomes of COVID-19 infection.

\section{Conclusion}

Our study did not demonstrate increased susceptibility or worse outcomes of COVID-19 infection among AA pregnant women. We did not find any evidence of vertical transmission in the neonates. Placental pathology in these patients revealed nonspecific findings. As this pandemic evolves, more information on pregnant women and perinatal outcomes will improve our understanding.

\section{Authors' Contributions}

S.J. and S.B. conceptualized and designed the study, collected data, drafted the initial manuscript, interpreted and analyzed the data, reviewed, and revised the manuscript critically for important intellectual content. S.M.J., F.Q., G.N., and S.B. contributed to design of study, did interpretation and analysis of data, and reviewed and revised the manuscript critically for important intellectual content. P.V. and C.A. collected data, reviewed and revised the manuscript critically for important intellectual content. All authors approved the final manuscript as submitted and agree to be accountable for all aspects of the work.

\section{Funding}

None.

\section{Conflict of Interest}

None declared.

\section{References}

1 WHO characterizes COVID-19 as a pandemic. 2020. Accessed July 31, 2020 at: https://www.who.int/emergencies/diseases/novel-coronavirus-2019/events-as-they-happen

2 Wu JT, Leung K, Bushman M, et al. Estimating clinical severity of COVID-19 from the transmission dynamics in Wuhan, China. Nat Med 2020;26(04):506-510 
3 CDC COVID-19 in Racial and Ethnic Minority Groups. Published 2020. Accessed July 24, 2020 at: https://www.cdc.gov/coronavirus/2019-ncov/need-extra-precautions/racial-ethnic-minorities. html

4 Kim SJ, Bostwick W. Social vulnerability and racial inequality in COVID-19 deaths in Chicago. Health Educ Behav 2020;47(04): 509-513

5 Yancy CW. COVID-19 and African Americans. JAMA 2020;323 (19):1891-1892

6 Wei M, Yuan J, Liu Y, Fu T, Yu X, Zhang ZJ. Novel coronavirus infection in hospitalized infants under 1 year of age in China. JAMA 2020;323(13):1313-1314

7 Chen H, Guo J, Wang C, et al. Clinical characteristics and intrauterine vertical transmission potential of COVID-19 infection in nine pregnant women: a retrospective review of medical records. Lancet 2020;395(10226):809-815

8 Chen Y, Peng H, Wang L, et al. Infants born to mothers with a new coronavirus (COVID-19). Front Pediatr 2020;8:104

9 Bianco A, Buckley AB, Overbey J, et al. Testing of patients and support persons for coronavirus disease 2019 (COVID-19) infection before scheduled deliveries. Obstet Gynecol 2020;136(02): 283-287

10 Savasi VM, Parisi F, Patanè L, et al. Clinical findings and disease severity in hospitalized pregnant women with coronavirus disease 2019 (COVID-19). Obstet Gynecol 2020;136(02): 252-258

11 Zaigham M, Andersson O. Maternal and perinatal outcomes with COVID-19: A systematic review of 108 pregnancies. Acta Obstet Gynecol Scand 2020;99(07):823-829

12 Alzamora MC, Paredes T, Caceres D, Webb CM, Valdez LM, La Rosa M. Severe COVID-19 during pregnancy and possible vertical transmission. Am J Perinatol 2020;37(08):861-865

$13 \mathrm{Ng}$ WF, Wong SF, Lam A, et al. The placentas of patients with severe acute respiratory syndrome: a pathophysiological evaluation. Pathology 2006;38(03):210-218

14 Baergen RN, Heller DS. Placental pathology in COVID-19 positive mothers: preliminary findings. Pediatr Dev Pathol 2020;23(03): 177-180

15 Shanes ED, Mithal LB, Otero S, Azad HA, Miller ES, Goldstein JA. Placental pathology in COVID-19. Am J Clin Pathol 2020;154(01): 23-32

16 Management of person with COVID-19 COVID-19 Treatment guidelines. Published 2020. Accessed 2020 at: https://www.cdc. gov/coronavirus/2019-ncov/hcp/clinical-guidance-management-patients.html

17 AAP AAP issues guidance on infants born to mothers with suspected or confirmed COVID-19. Published 2020. Accessed
April 2, 2020 at: https://www.aappublications.org/news/2020/ 04/02/infantcovidguidance 040220

18 Khong TY, Mooney EE, Ariel I, et al. Sampling and definitions of placental lesions: amsterdam placental workshop group consensus statement. Arch Pathol Lab Med 2016;140(07):698-713

19 Khong TY, Bendon RW, Qureshi F, et al. Chronic deciduitis in the placental basal plate: definition and interobserver reliability. Hum Pathol 2000;31(03):292-295

20 Kim CJ, Romero R, Kusanovic JP, et al. The frequency, clinical significance, and pathological features of chronic chorioamnionitis: a lesion associated with spontaneous preterm birth. Mod Pathol 2010;23(07):1000-1011

21 Sutton D, Fuchs K, D’Alton M, Goffman D. Universal screening for SARS-CoV-2 in women admitted for delivery. N Engl J Med 2020; 382(22):2163-2164

22 Elshafeey F, Magdi R, Hindi N, et al. A systematic scoping review of COVID-19 during pregnancy and childbirth. Int J Gynaecol Obstet 2020;150(01):47-52

23 Sethuraman N, Jeremiah SS, Ryo A. Interpreting diagnostic tests for SARS-CoV-2. JAMA 2020;323(22):2249-2251

24 Dong L, Tian J, He S, et al. Possible vertical transmission of SARSCoV-2 from an infected mother to her newborn. JAMA 2020;323 (18): $1846-1848$

25 Yang Z, Liu Y. Vertical transmission of severe acute respiratory syndrome coronavirus 2: a systematic review. Am J Perinatol 2020;37(10):1055-1060

26 Wong SF, Chow KM, Leung TN, et al. Pregnancy and perinatal outcomes of women with severe acute respiratory syndrome. Am J Obstet Gynecol 2004;191(01):292-297

27 Kim CJ, Romero R, Chaemsaithong P, Kim JS. Chronic inflammation of the placenta: definition, classification, pathogenesis, and clinical significance. Am J Obstet Gynecol 2015;213(04, Suppl): S53-S69

28 Romero R, Kim YM, Pacora P, et al. The frequency and type of placental histologic lesions in term pregnancies with normal outcome. J Perinat Med 2018;46(06):613-630

29 Ogino S, Redline RW. Villous capillary lesions of the placenta: distinctions between chorangioma, chorangiomatosis, and chorangiosis. Hum Pathol 2000;31(08):945-954

30 Stanek J. Chorangiosis of chorionic villi: what does it really mean? Arch Pathol Lab Med 2016;140(06):588-593

31 Stanek J, Biesiada J. Clustering of maternal-fetal clinical conditions and outcomes and placental lesions. Am J Obstet Gynecol 2012;206(06):493.e1-493.e8

32 Mayhew TM. Changes in fetal capillaries during preplacental hypoxia: growth, shape remodelling and villous capillarization in placentae from high-altitude pregnancies. Placenta 2003;24(2-3):191-198 